\title{
Anatomic or Functional Evaluation as an Initial Test for Stable Coronary Artery Disease: A Propensity Score Analysis
}

\author{
Gyung-Min Park ${ }^{1}$, Young-Hak Kim², Sung-Cheol Yun ${ }^{3}$, Jung-Min Ahn², Hyo-In Choi², Jae-Hyung Roh ${ }^{2}$, \\ Pil Hyung Lee ${ }^{2}$, Mineok Chang ${ }^{2}$, Sang Gyu Lee ${ }^{4}$, Min-Woo Jo ${ }^{5}$, Duk-Woo Park ${ }^{2}$, Soo-Jin Kang ${ }^{2}$, Seung-Whan Lee², \\ Cheol Whan Lee ${ }^{2}$, Dae Hyuk Moon ${ }^{6}$, Seong-Wook Park², and Seung-Jung Park ${ }^{2}$ \\ ${ }^{1}$ Department of Cardiology, Daejeon St. Mary's Hospital, College of Medicine, The Catholic University of Korea, Daejeon, Korea; \\ ${ }^{2}$ Department of Cardiology, Asan Medical Center, University of Ulsan College of Medicine, Seoul, Korea; ${ }^{3}$ Department of \\ Biostatistics, Asan Medical Center, University of Ulsan College of Medicine, Seoul, Korea; ${ }^{4}$ Department of Hospital Management, \\ Graduate School of Public Health, Yonsei University, Seoul, Korea; ${ }^{5}$ Department of Preventive Medicine, Asan Medical Center, \\ University of Ulsan College of Medicine, Seoul, Korea; and ${ }^{6}$ Department of Nuclear Medicine, Asan Medical Center, University of \\ Ulsan College of Medicine, Seoul, Korea
}

\begin{abstract}
Little data are available to compare the clinical implications of coronary angiography (CAG) or myocardial perfusion imaging (MPI) as an initial evaluation for stable coronary artery disease (CAD). Methods: From national health insurance claims data in South Korea, patients aged 18 y or older without a known history of CAD, who underwent CAG or MPI for the diagnosis of stable CAD between 2009 and 2013, were enrolled. Patients were divided into CAG $(n=117,134)$ and MPI $(n=$ $19,932)$ groups. The primary endpoint, defined as a composite of allcause death and myocardial infarction, was compared by a propensity score analysis between the 2 groups. Results: There was a significant increase (39\%) in the annual rate of CAG from 23,985 in 2009-2010 to 33,373 in 2012-2013. However, a substantial reduction (41\%) in the annual MPI rate was also noted from 6,389 in 2009-2010 to 3,790 in 2012-2013. During the follow-up period (median, 2.4 y; interquartile range, 1.5-3.5), coronary revascularization was more frequently performed in the CAG group (adjusted hazard ratio [aHR] of CAG, 24.15; 95\% confidence interval [Cl], 19.66-29.68; $P<0.001$ ). However, the incidence of the primary endpoint was significantly higher in the CAG group (aHR, 1.26; 95\% Cl, 1.17-1.36; $P<0.001$ ). The individual endpoints of death (aHR, 1.16; $95 \% \mathrm{Cl}, 1.06-1.25 ; P=0.001)$ and myocardial infarction (aHR, 1.95; 95\% Cl, 1.60-2.36; $P<0.001$ ) were also higher in the CAG group. Conclusion: As an initial diagnostic test in patients with stable CAD, MPI is associated with a better clinical outcomes than CAG.
\end{abstract}

Key Words: coronary artery disease; diagnostic test; coronary angiography; myocardial perfusion imaging

J Nucl Med 2016; 57:1364-1369

DOI: 10.2967/jnumed.115.169318

C oronary artery disease (CAD) is the leading cause of death (1). To evaluate CAD, invasive coronary angiography (CAG) has been regarded as the reference standard (2). However, substantial

Received Nov. 9, 2015; revision accepted Mar. 26, 2016.

For correspondence or reprints contact: Young-Hak Kim, Department of Cardiology, Asan Medical Center, University of Ulsan College of Medicine, 388-1 Poongnap-dong, Songpa-gu, Seoul, 138-736, Korea.

E-mail: mdyhkim@amc.seoul.kr

Published online Apr. 28, 2016.

COPYRIGHT (c) 2016 by the Society of Nuclear Medicine and Molecular Imaging, Inc. discrepancies between angiographic anatomic findings and functional severity of stenosis have been noted $(2,3)$. Additionally, coronary revascularization without documentation of ischemia using functional tests might lead to increased medical costs and deterioration in clinical prognoses (4-6).

Myocardial perfusion imaging (MPI) has been widely used in clinical practice to detect ischemia and assess its severity in patients with CAD (7). Previous studies showed that MPI-guided clinical decision making might be cost-effective and useful to improve short- and long-term prognoses (7-9). However, with recent advances in devices and adjuvant pharmacologic agents, the threshold for an invasive procedure has been reduced, and functional evaluations, including MPI, have been underutilized $(10,11)$.

The currently accepted guidelines have advocated for noninvasive functional testing before invasive angiography $(2,12)$. However, this has not yet been properly incorporated into clinical practice $(11,13)$. When taking the entire clinical practice into account, there are limited data to compare the clinical implications of anatomic versus functional evaluation as the initial test for stable CAD. Therefore, using claims data of the National Health Insurance (NHI) in South Korea, we sought to assess the clinical outcomes of patients with stable CAD who underwent an initial diagnostic evaluation using either CAG or MPI.

\section{MATERIALS AND METHODS}

\section{Data Sources}

This study was approved by the local Institutional Review Board of the Asan Medical Center, Seoul, Korea, which waived the informed consent requirement. It was conducted with the permission of the National Strategic Coordinating Center of Clinical Research and the Health Insurance Review \& Assessment Service (HIRA) in Korea. Because South Korea has an NHI system, all health care providers had to join this system on a fee-for-service basis. The HIRA is a quasigovernmental organization that systematically reviews medical fees to minimize the risk of redundant and unnecessary medical services. Consequently, all NHI claims are reviewed by the HIRA (14). In this present study, data from 2009-2013 claims records of the HIRA were used. Diagnosis codes were used in the International Classification of Diseases, 10th Revision (ICD10) (15). Procedures are identified by codes from the HIRA database (14).

\section{Study Population}

From the claims database of the HIRA between July 2009 and June 2013, we identified patients aged 18 y and older who had undergone 
CAG (HA670) or MPI (HC292, HC297, and HC298) for the diagnosis of CAD (ICD-10 codes I20.X-25.X). Patients with at least 6 mo of eligibility before the index test were selected. Specifically, patients with an index test performed to diagnose acute myocardial infarction (MI) (I21.X-I22.X) or unstable angina (I20.0) were excluded to focus on stable CAD. We excluded patients if the HIRA database indicated that they had a history of CAD (ICD-10 codes I20.X-25.X) within 6 mo of the index day and if CAG and MPI had been documented on the same day. Additionally, patients were excluded if other diagnostic tests for CAD, such as exercise electrocardiogram (E6543) and coronary CT angiography (HA474), were performed within 3 mo of the index day to exclude test-driven procedures. The ICD-10 codes were used to identify comorbid conditions $(15,16)$. The Charlson comorbidity index was obtained from the ICD-10 codes (15).

\section{Clinical Outcomes}

The primary endpoint of this study was a composite of all-cause death and MI. We also examined coronary revascularization. In subjects with multiple primary events, the first event was considered to be the component of the composite outcome. Death was identified by all in- and out-patient claims that indicated death. MI was defined using the hospital discharge databases of the HIRA (ICD-10 codes I21.X-22.X). Coronary revascularizations in the HIRA database were identified using the procedure codes of percutaneous coronary intervention (M6551, M6552, M6561-4, M6571, and M6572) and coronary artery bypass surgery (O1641, O1642, O1647, OA641, OA642, and OA647) (14). In this current study, to evaluate clinical outcomes, the HIRA database was used until December 2013.

\section{Statistical Analysis}

Categoric variables are presented as frequencies and percentages, and continuous variables are expressed as means with the SDs. A Pearson $\chi^{2}$ or Fisher exact test was used for categoric variables, and a $t$ test (or Mann-Whitney $U$ test) was used to compare continuous numeric variables, as appropriate.

For clinical outcomes, we calculated the incidence rate per 1,000 person-year as the number of cases divided by the 1,000 person-year. Confidence intervals (CIs) for these rates were estimated assuming a Poisson distribution. Unadjusted outcomes between 2 groups were compared using the Cox proportional hazards models. Then, to reduce the impact of test selection bias and potential confounding factors in an observational study, we performed an adjustment for differences in baseline characteristics of patients using a weighted Cox proportional hazards regression model with an inverse probability of treatment weighting (17). When that technique was used, the weights for patients undergoing CAG were the inverse of 1 - propensity score, and weights for patients receiving MPI were the inverse of the propensity score. The propensity scores were estimated without regard to outcomes by multiple logistic regression analysis. A full nonparsimonious model was developed that included all variables shown in Table 1. Using the estimated weights, we examined the similarity between the

TABLE 1

Characteristics of Patients with Stable CAD Undergoing Initial Diagnostic Evaluation with Either CAG or MPI

\begin{tabular}{|c|c|c|c|}
\hline \multirow[b]{2}{*}{ Characteristic } & \multicolumn{2}{|c|}{ Overall $(n=137,066)$} & \multirow[b]{2}{*}{$P$} \\
\hline & CAG $(n=117,134)$ & $\operatorname{MPI}(n=19,932)$ & \\
\hline Age (y) & $60.6 \pm 12.1$ & $61.7 \pm 12.2$ & $<0.001$ \\
\hline Sex, male, $n(\%)$ & $63,912(54.6)$ & $10,422(52.3)$ & $<0.001$ \\
\hline No. of patients enrolled (\%) & & & $<0.001$ \\
\hline July 2009 to June 2010 & $23,985(20.5)$ & $6,389(32.1)$ & \\
\hline July 2010 to June 2011 & $28,193(24.1)$ & $5,513(27.7)$ & \\
\hline July 2011 to June 2012 & $31,583(27.0)$ & $4,240(21.3)$ & \\
\hline July 2012 to June 2013 & $33,373(28.5)$ & $3,790(19.0)$ & \\
\hline \multicolumn{4}{|l|}{ No. of comorbid conditions (\%) } \\
\hline Diabetes & $23,380(20.0)$ & $4,864(24.4)$ & $<0.001$ \\
\hline Diabetes with chronic complications & $11,520(9.8)$ & $2,115(10.6)$ & 0.001 \\
\hline Hyperlipidemia & $33,591(28.7)$ & $6,995(35.1)$ & $<0.001$ \\
\hline Hypertension & $52,629(44.9)$ & $10,184(51.1)$ & $<0.001$ \\
\hline Congestive heart failure & $6,844(5.8)$ & $830(4.2)$ & $<0.001$ \\
\hline Arrhythmia & $7,686(6.6)$ & $1,492(7.5)$ & $<0.001$ \\
\hline Valvular disease & $1,622(1.4)$ & $269(1.4)$ & 0.694 \\
\hline Peripheral vascular disease & $13,869(11.8)$ & $2,345(11.8)$ & 0.761 \\
\hline Cerebrovascular disease & $14,026(12.0)$ & $2,522(12.7)$ & 0.007 \\
\hline Chronic pulmonary disease & $25,327(21.6)$ & $4,076(20.5)$ & $<0.001$ \\
\hline Moderate to severe liver disease & $416(0.4)$ & $179(0.9)$ & $<0.001$ \\
\hline Renal disease & $3,107(2.7)$ & $991(5.0)$ & $<0.001$ \\
\hline Cancer & $6,246(5.3)$ & $2,993(15.0)$ & $<0.001$ \\
\hline Rheumatic disease & $3,533(3.0)$ & $817(4.1)$ & $<0.001$ \\
\hline Charlson comorbidity index & $1.5 \pm 1.8$ & $2.0 \pm 2.2$ & $<0.001$ \\
\hline
\end{tabular}

Data are expressed as $n$, with percentages in parentheses, and mean \pm SD. 
CAG and MPI groups by calculating standardized differences for each of the baseline variables listed in Table 1. All standardized differences for each of the baseline variables were less than 0.05 (5\%) (Supplemental Table 1; supplemental materials are available at http://jnm.snmjournals. org). The results of inverse probability of treatment weighting were verified by those of propensity score matching and propensity score adjustment methods. The propensity score-matched pairs were created by matching between CAG and MPI subjects on the logit of the propensity score using calipers of width equal to 0.2 of the SD of the logit of the propensity score (18). Additionally, to reduce possible associations between the use of a diagnostic test and the characteristics of the hospital, we performed a site adjustment using the unique hospital identification number from claims data. For the hospital-level adjustment, we analyzed subpopulation data, which included only hospitals that could perform both CAG and MPI tests for the diagnosis of stable CAD (Supplemental Table 2). In subpopulation analyses, the risks of clinical endpoints were compared using the weighted Cox regression models with robust standard errors that accounted for the clustering of hospital level.

All reported $P$ values are 2 -sided. A $P$ value of less than 0.05 was considered to indicate statistical significance. Data management and statistical analyses were conducted using SAS (version 9.1; SAS Institute Inc.).

\section{RESULTS}

\section{Study Population and Characteristics}

A total of 620,512 patients undergoing CAG or MPI between July 2009 and June 2013 were identified from the claims database of HIRA. Among these cases, 137,066 met the eligibility criteria and were selected as the study population. Patients were divided into CAG $(n=117,134)$ and MPI $(n=19,932)$ groups (Fig. 1$)$.

Table 1 lists the baseline clinical characteristics of patients according to the CAG or MPI test. The mean age of the study population was $60.7 \pm 12.1 \mathrm{y}$, and 74,334 (54.2\%) patients were men. Patients undergoing MPI were older and had greater comorbid conditions than those in the CAG group.

\section{Trends in Use of CAG and MPI Across South Korea}

Between July 2009 and June 2013, claims data of the HIRA indicated that CAG became more prevalent over time, increasing from 23,985 in $2009-2010$ to 33,373 in 2012-2013 (a 39\% increase).

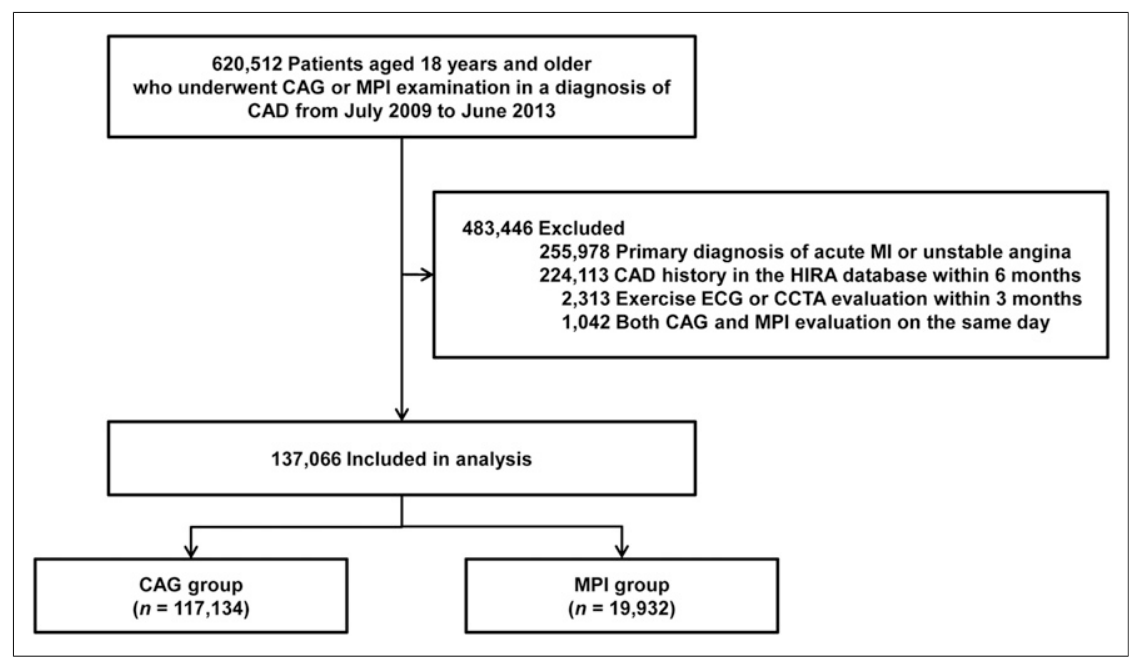

FIGURE 1. Overview of study population. CCTA = coronary CT angiography; ECG = electrocardiogram.
Additionally, a $13 \%$ increase in the number of CAG-providing hospitals occurred between 2009-2010 and 2012-2013 (154 vs. 174 hospitals), with a gradual increase in the mean caseload per hospital (155.7 \pm 174.3 in 2009-2010 vs. $191.8 \pm 182.9$ in 2012-2013).

However, there was a $41 \%$ reduction in the annual MPI rate from 6,389 in 2009-2010 to 3,790 in 2012-2013, without a significant difference in the number of MPI-providing hospitals throughout the $4-y$ period (59 vs. 54 hospitals). Consequently, the reduction in national MPI rates resulted in a $35 \%$ reduction in the mean caseload per hospital (108.3 \pm 499.7 in 2009-2010 vs. $70.2 \pm 310.1$ in 2012-2013; Table 2).

\section{Increased Coronary Revascularization in CAG Group Is Not Associated with Better Clinical Outcomes}

During the follow-up period (median, $2.4 \mathrm{y}$; interquartile range, 1.5-3.5), 6,080 (4.4\%) events of the primary endpoint occurred, including 4,944 (3.6\%) deaths and 1,401 (1.0\%) MIs. Coronary revascularization was performed in 15,096 (11.0\%) patients $(15,050$ [11.0\%] percutaneous coronary interventions and 49 [0.04\%] coronary artery bypass surgeries). There was no significant difference between the CAG and MPI groups in the unadjusted incidence of the primary endpoint. However, among the primary endpoints, the unadjusted incidence of all-cause death was significantly lower in the CAG group, but the unadjusted incidence of MI was significantly higher in the CAG group (Table 3).

After adjustments to the weighted Cox proportional hazards regression models with the inverse probability of treatment weighting method, coronary revascularization was significantly greater in the CAG group. However, the adjusted incidence of the primary endpoint was significantly higher in the CAG group. The individual endpoints of death and MI were also higher in the CAG group (Table 3). Figure 2 shows the cumulative incidence rates for adjusted all-cause death with and without MI between 2 groups. Additionally, even after we incorporated a site adjustment using the unique hospital identification number, the unfavorable pattern of adjusted all (adjusted hazard ratio [aHR] of CAG, 1.26; 95\% CI, 1.16-1.36; $P<0.001$ ) and individual (death, aHR, 1.19; 95\% CI, 1.09-1.29; $P<0.001$ and MI, aHR, 1.81; 95\% CI, 1.49-2.20; $P<0.001$ ) incidences was unchanged in the CAG group (Supplemental Table 3). The results of propensity score matching and propensity score adjustment methods were also favorable to the MPI group (Supplemental Table 4).

\section{DISCUSSION}

In the present analysis of NHI claims data for South Korea, our main findings were as follows: between 2009 and 2013, a substantial increase in CAG use rates was observed, but MPI use rates steadily decreased, and although coronary revascularization was more frequently performed in the CAG group, the use of CAG was associated with a greater risk of all causes of death or MI than was the use of MPI, even after adjusting for potentially confounding variables.

There are few data available to guide decision making regarding the use of an initial test for a stable CAD (19). There is 
TABLE 2

Patient and Hospital Characteristics of CAG and MPI in South Korea Between 2009 and 2013

\begin{tabular}{|c|c|c|c|c|c|}
\hline Characteristic & $\begin{array}{c}\text { July } 2009 \text { to } \\
\text { June } 2010\end{array}$ & $\begin{array}{l}\text { July } 2010 \text { to } \\
\text { June } 2011\end{array}$ & $\begin{array}{l}\text { July } 2011 \text { to } \\
\text { June } 2012\end{array}$ & $\begin{array}{c}\text { July } 2012 \text { to } \\
\text { June } 2013\end{array}$ & $P$ \\
\hline \multicolumn{6}{|l|}{ CAG } \\
\hline Age (y) & $60.0 \pm 12.2$ & $60.4 \pm 12.1$ & $60.9 \pm 12.1$ & $60.9 \pm 12.1$ & $<0.001$ \\
\hline Age groups $(y)$ & & & & & $<0.001$ \\
\hline$<55$ & $8,184(34.1)$ & $9,162(32.5)$ & $9,719(30.8)$ & $10,301(30.9)$ & \\
\hline $55-64$ & $6,722(28.0)$ & $8,048(28.6)$ & $9,388(29.7)$ & $9,825(29.4)$ & \\
\hline$\geq 65$ & $9,079(37.9)$ & $10,983(39.0)$ & $12,476(39.5)$ & $13,247(39.7)$ & \\
\hline Male sex $(n)$ & $12,881(53.7)$ & $15,259(54.1)$ & $17,321(54.8)$ & $18,451(55.3)$ & 0.001 \\
\hline No. of hospitals providing a procedure & 154 & 157 & 161 & 174 & \\
\hline Procedure volume of a hospital, per year & $155.7 \pm 174.3$ & $179.6 \pm 189.7$ & $196.2 \pm 188.7$ & $191.8 \pm 182.9$ & 0.047 \\
\hline \multicolumn{6}{|l|}{ MPI } \\
\hline Age $(y)$ & $61.0 \pm 12.2$ & $61.5 \pm 12.1$ & $62.0 \pm 12.3$ & $62.9 \pm 12.3$ & $<0.001$ \\
\hline Age groups $(y)$ & & & & & $<0.001$ \\
\hline$<55$ & $1,910(29.9)$ & $1,610(29.2)$ & $1,153(27.2)$ & $928(24.5)$ & \\
\hline $55-64$ & $1,704(26.7)$ & $1,448(26.3)$ & $1,171(27.6)$ & $1,013(26.7)$ & \\
\hline$\geq 65$ & $2,775(43.4)$ & $2,455(44.5)$ & $1,916(45.2)$ & $1,849(48.8)$ & \\
\hline Male sex $(n)$ & $3,237(50.7)$ & $2,925(53.1)$ & $2,298(54.2)$ & $1,962(51.8)$ & 0.002 \\
\hline No. of hospitals providing a procedure & 59 & 56 & 54 & 54 & \\
\hline Procedure volume of a hospital, per year & $108.3 \pm 499.7$ & $98.4 \pm 479.7$ & $78.5 \pm 365.2$ & $70.2 \pm 310.1$ & 0.537 \\
\hline
\end{tabular}

still a lack of evidence regarding which diagnostic modality for stable CAD improves clinical outcomes. In several previous reports, the initial diagnostic test with MPI showed a favorable clinical outcome, but those studies analyzed limited populations $(19,20)$. Additionally, because of relatively low hard clinical event rates in patients with stable $\mathrm{CAD}$, they are insufficient to determine the relationship between an initial diagnostic test and hard clinical events, such as death and MI. Therefore, considering the nationwide situation in clinical practices, this present study was designed. Well-controlled and reliable data from the HIRA database in Korea (i.e., a quasigovernmental organization) enabled qualified analyses of clinical outcomes after the initial analysis for stable CAD (14).

The present study showed a significant increase $(39 \%)$ in the annual rate of CAG in South Korea between 2009 and 2013. However, a substantial reduction $(41 \%)$ in the rate of MPI with a roughly linear trend was noted during the same period. Similar to previous studies $(11,21)$, our study also demonstrated that most patients with stable CAD did not have the documentation of ischemia by noninvasive testing before an invasive procedure. Additionally, although an increase in the number of CAG-providing hospitals was observed throughout the 4-y period, there was no significant change in the number of MPI-providing hospitals. This trend suggests a sizeable shift in clinical practice patterns away from noninvasive functional tests toward invasive procedures. In the guidelines, noninvasive functional tests are recommended to confirm the diagnosis of $\mathrm{CAD}$, to document ischemia in patients with stable symptoms, and to stratify the risk of patients with stable angina before an invasive test $(2,12)$. However, our study showed the existence of a considerable gap between the guidelines and real clinical practice. An even more important finding was that the difference increased as time passed. Because previous and our studies demonstrated that the adherence to guidelines improves clinical outcomes in patients with CAD $(22,23)$, further implementation of established guidelines is needed.

Historically, most studies of revascularization have been based on and reported according to angiographic criteria (12). However, previous studies with MPI showed that angiographic stenosis is not equivalent to functionally significant stenosis $(24,25)$. A recent study with an assessment of fractional flow reserves also showed that CAG is not always accurate for assessing the functional significance of a coronary stenosis, regardless of the angiographic severity (3). Unnecessary revascularization can lead to increased costs, radiation exposure, and procedural complications without clinical benefits $(4,5)$. In our present study, the CAG group underwent more coronary revascularization. Notably, the increase of coronary revascularization in the CAG group was not associated with improvements in primary endpoints, such as all-cause death and MI. Potentially, coronary revascularization in the CAG group might have been performed in patients who would not have clinically benefited from the procedure. Therefore, on the basis of these findings, CAG should be carefully selected as an initial diagnostic modality for patients with stable CAD.

For patients with stable CAD, the role of prompt coronary revascularization has been a controversial issue $(2,12)$. In the Clinical Outcomes Using Revascularization and Aggressive Drug Evaluation trial, routine revascularization to optimize medical therapy did not reduce the long-term rates of death or nonfatal MI (26). However, in the Clinical Outcomes Using Revascularization and Aggressive Drug Evaluation nuclear substudy, adding 
TABLE 3

Clinical Outcomes in Crude and Adjusted with Inverse Probability Treatment Weight Methods in Patients Undergoing CAG or MPI

\begin{tabular}{|c|c|c|c|c|c|c|}
\hline \multirow[b]{3}{*}{ Clinical outcome } & \multirow{2}{*}{\multicolumn{2}{|c|}{ Incidence rate* }} & \multicolumn{4}{|c|}{ CAG compared with MPI } \\
\hline & & & \multirow{2}{*}{$\begin{array}{l}\text { Crude hazard } \\
\text { ratio }(95 \% \mathrm{Cl})\end{array}$} & \multirow[b]{2}{*}{$P$} & \multirow{2}{*}{$\begin{array}{l}\text { Adjusted hazard } \\
\text { ratio }(95 \% \mathrm{Cl})\end{array}$} & \multirow[b]{2}{*}{$P$} \\
\hline & MPI (95\% Cl) & CAG $(95 \% \mathrm{Cl})$ & & & & \\
\hline \multicolumn{7}{|l|}{ Crude } \\
\hline All-cause death & $15.28(14.25-16.30)$ & $14.58(14.13-15.02)$ & $0.90(0.83-0.96)$ & 0.003 & & \\
\hline MI & $2.35(1.96-2.75)$ & $4.43(4.19-4.68)$ & $1.75(1.46-2.09)$ & $<0.001$ & & \\
\hline Coronary revascularization & $1.88(1.53-2.24)$ & $59.13(58.18-60.07)$ & $25.33(20.96-30.60)$ & $<0.001$ & & \\
\hline All-cause death/MI & $17.20(16.11-18.29)$ & $18.39(17.89-18.89)$ & $1.00(0.93-1.07)$ & 0.999 & & \\
\hline $\begin{array}{l}\text { All-cause death/MI/coronary } \\
\text { revascularization }\end{array}$ & $18.95(17.81-20.10)$ & 77.07 (75.98-78.17) & $3.42(3.22-3.64)$ & $<0.001$ & & \\
\hline \multicolumn{7}{|l|}{$\begin{array}{l}\text { Adjusted with inverse } \\
\text { probability of treatment } \\
\text { weighting }\end{array}$} \\
\hline All-cause death & $12.87(11.80-13.93)$ & $15.02(14.53-15.52)$ & & & $1.16(1.06-1.25)$ & 0.001 \\
\hline MI & $2.26(1.79-2.73)$ & $4.46(4.20-4.71)$ & & & $1.95(1.60-2.36)$ & $<0.001$ \\
\hline Coronary revascularization & $2.20(1.65-2.76)$ & $58.00(57.05-58.94)$ & & & 24.15 (19.66-29.68) & $<0.001$ \\
\hline All-cause death/MI & $14.79(13.63-15.95)$ & $18.85(18.30-19.40)$ & & & $1.26(1.17-1.36)$ & $<0.001$ \\
\hline $\begin{array}{l}\text { All-cause death/Ml/coronary } \\
\text { revascularization }\end{array}$ & $16.85(15.56-18.14)$ & $76.42(75.30-77.53)$ & & & $4.24(3.96-4.54)$ & $<0.001$ \\
\hline
\end{tabular}

${ }^{*}$ Incidence rate per 1,000 person-year.

revascularization to medical therapy resulted in a greater reduction in inducible ischemia, particularly if baseline ischemia was moderate to severe $(\geq 10 \%)$. Patients with a significant reduction in myocardial ischemia ( $\geq 5 \%$ ) had lower risk for death or MI (27). Moreover, in previous studies, stress testing before cardiac catheterization has been associated with lower medical costs and rates of revascularization without adverse effects on cardiac death or MI (19,21). The guidelines, accordingly, support a strategy of ischemia-guided revascularization for the treatment of patients with stable CAD $(2,12)$. These findings highlight the pivotal role for a functional evaluation in distinguishing patients who require coronary revascularization from those with stable CAD (28).

In the present study, the unadjusted incidence of all-cause death was significantly higher in the MPI group. This finding might be partly attributable to the characteristics of patients in the MPI group, as they were older and had more comorbidities than those in

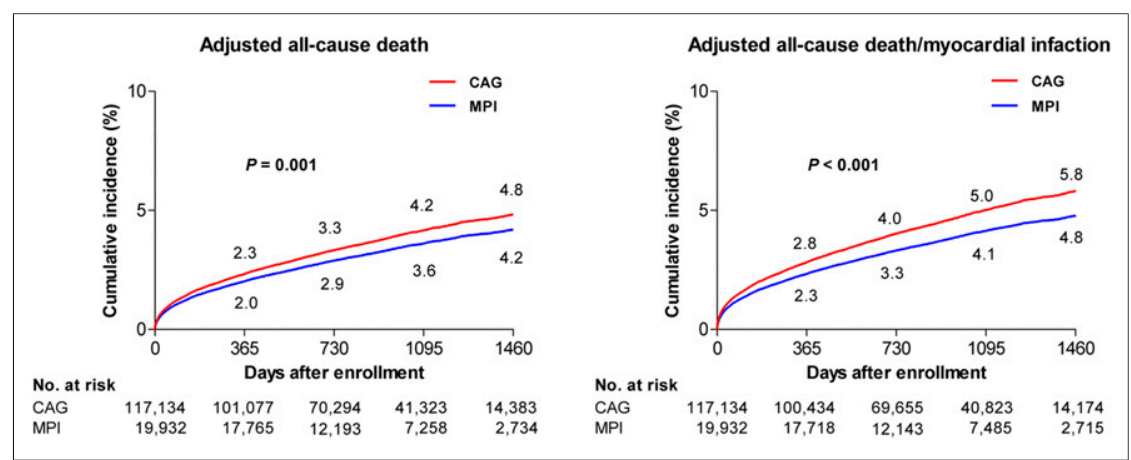

FIGURE 2. Cumulative incidence rates for adjusted all-cause death with and without MI between CAG and MPI groups. the CAG group. This finding also implies that CAG was performed for relatively healthy patients with preferable physical conditions. However, after adjustments with possible confounding variables, an opposite result was obtained. Additionally, the unfavorable incidence rates of MI were maintained in patients undergoing CAG, irrespective of statistical adjustments. One possible explanation for these findings is that the initial test with CAG might lead to an unnecessary procedure, which could increase the risk of procedurerelated complications, such as bleeding, renal dysfunction, in-stent restenosis, stent thrombosis, MI, stroke, or death. Therefore, to improve the prognosis of patients by avoiding unnecessary procedure-related complications, this function-guided strategy should be applied to evaluate stable CAD.

Our study had several limitations. First, our analysis was based on administrative data from the HIRA in South Korea. Similar to previous studies using administrative databases, we had no clinical data regarding the symptoms or test findings of patients. Thus, our results might be limited by uncertainties in patient selection and unmeasured confounding variables that may affect patients' management $(11,16)$. Second, although we used a database from a quasigovernmental organization, there was a possibility that these data did not fully reflect patient outcomes. Additionally, we did not specify the cause of death. Third, our study did not consider other diagnostic tests, such as PET scanning, MRI, stress echocardiography, or fractional flow reserve. However, considering the limited applicability and relatively high cost of these diagnostic 
tests in South Korea during the study period, they would not have changed our overall findings. Finally, our study only included a Korean population. Therefore, it might not be possible to generalize our practice pattern and findings on the clinical impact of an initial test to other countries. Nonetheless, the underutilization of stress testing, as indicated by large registry studies from the United States $(11,21,29)$, indicates that our results might be widely applicable to everyday practice.

\section{CONCLUSION}

From an analysis using the NHI claims data in South Korea, the rate of CAG significantly increased between 2009 and 2013, but there was a substantial reduction in the MPI rate. Coronary revascularization was significantly higher with $\mathrm{CAG}$ as the initial test compared with MPI. However, patients with stable CAD undergoing CAG were associated with a higher risk of all causes of death or MI than those undergoing MPI.

\section{DISCLOSURE}

The costs of publication of this article were defrayed in part by the payment of page charges. Therefore, and solely to indicate this fact, this article is hereby marked "advertisement" in accordance with 18 USC section 1734 . This study was supported by a grant from the Korea Healthcare Technology R\&D Project, Ministry of Health and Welfare, Republic of Korea (A102065, HI12C0630, and HI10C2020). No other potential conflict of interest relevant to this article was reported.

\section{REFERENCES}

1. Nabel EG, Braunwald E. A tale of coronary artery disease and myocardial infarction. N Engl J Med. 2012;366:54-63.

2. Windecker S, Kolh P, Alfonso F, et al. 2014 ESC/EACTS guidelines on myocardial revascularization: The Task Force on Myocardial Revascularization of the European Society of Cardiology (ESC) and the European Association for Cardio-Thoracic Surgery (EACTS) developed with the special contribution of the European Association of Percutaneous Cardiovascular Interventions (EAPCI). Eur Heart J. 2014;35:2541-2619.

3. Tonino PA, Fearon WF, De Bruyne B, et al. Angiographic versus functional severity of coronary artery stenoses in the FAME study fractional flow reserve versus angiography in multivessel evaluation. J Am Coll Cardiol. 2010;55: 2816-2821.

4. Pijls NH, Fearon WF, Tonino PA, et al. Fractional flow reserve versus angiography for guiding percutaneous coronary intervention in patients with multivessel coronary artery disease: 2-year follow-up of the FAME (Fractional Flow Reserve Versus Angiography for Multivessel Evaluation) study. J Am Coll Cardiol. 2010;56:177-184.

5. Fearon WF, Bornschein B, Tonino PA, et al. Economic evaluation of fractional flow reserve-guided percutaneous coronary intervention in patients with multivessel disease. Circulation. 2010;122:2545-2550.

6. De Bruyne B, Pijls NH, Kalesan B, et al. Fractional flow reserve-guided PCI versus medical therapy in stable coronary disease. N Engl J Med. 2012;367:991-1001.

7. Marcassa C, Bax JJ, Bengel F, et al. Clinical value, cost-effectiveness, and safety of myocardial perfusion scintigraphy: a position statement. Eur Heart J. 2008;29:557-563.

8. Kim YH, Ahn JM, Park DW, et al. Impact of ischemia-guided revascularization with myocardial perfusion imaging for patients with multivessel coronary disease. J Am Coll Cardiol. 2012;60:181-190.

9. Hachamovitch R, Hayes SW, Friedman JD, Cohen I, Berman DS. Comparison of the short-term survival benefit associated with revascularization compared with medical therapy in patients with no prior coronary artery disease undergoing stress myocardial perfusion single photon emission computed tomography. Circulation. 2003;107:2900-2907.
10. Kim YH, Park SJ. Ischemia-guided percutaneous coronary intervention for patients with stable coronary artery disease. Circ J. 2013;77:1967-1974.

11. Lin GA, Dudley RA, Lucas FL, Malenka DJ, Vittinghoff E, Redberg RF. Frequency of stress testing to document ischemia prior to elective percutaneous coronary intervention. JAMA. 2008;300:1765-1773.

12. Levine GN, Bates ER, Blankenship JC, et al. 2011 ACCF/AHA/SCAI guideline for percutaneous coronary intervention: a report of the American College of Cardiology Foundation/American Heart Association Task Force on Practice Guidelines and the Society for Cardiovascular Angiography and Interventions. Circulation. 2011;124:e574-e651.

13. Deyell MW, Buller CE, Miller LH, et al. Impact of National Clinical Guideline recommendations for revascularization of persistently occluded infarct-related arteries on clinical practice in the United States. Arch Intern Med. 2011;171: 1636-1643.

14. Park GM, Han S, Kim SH, et al. Model for assessing cardiovascular risk in a Korean population. Circ Cardiovasc Qual Outcomes. 2014;7:944-951.

15. Quan H, Sundararajan V, Halfon P, et al. Coding algorithms for defining comorbidities in ICD-9-CM and ICD-10 administrative data. Med Care. 2005;43: 1130-1139.

16. Shreibati JB, Baker LC, Hlatky MA. Association of coronary CT angiography or stress testing with subsequent utilization and spending among Medicare beneficiaries. JAMA. 2011;306:2128-2136.

17. Robins JM, Hernan MA, Brumback B. Marginal structural models and causal inference in epidemiology. Epidemiology. 2000;11:550-560.

18. Rosenbaum PR. Observational Studies. New York, NY: Springer-Verlag; 1995.

19. Shaw LJ, Hachamovitch R, Berman DS, et al. The economic consequences of available diagnostic and prognostic strategies for the evaluation of stable angina patients: an observational assessment of the value of precatheterization ischemia. Economics of Noninvasive Diagnosis (END) Multicenter Study Group. J Am Coll Cardiol. 1999;33:661-669.

20. Yamauchi T, Tamaki N, Kasanuki H, et al. Optimal initial diagnostic strategies for the evaluation of stable angina patients: a multicenter, prospective study on myocardial perfusion imaging, computed tomographic angiography, and coronary angiography. Circ J. 2012;76:2832-2839.

21. Topol EJ, Ellis SG, Cosgrove DM, et al. Analysis of coronary angioplasty practice in the United States with an insurance-claims data base. Circulation. 1993;87:1489-1497.

22. Rogers AM, Ramanath VS, Grzybowski M, et al. The association between guideline-based treatment instructions at the point of discharge and lower 1-year mortality in Medicare patients after acute myocardial infarction: the American College of Cardiology's Guidelines Applied in Practice (GAP) initiative in Michigan. Am Heart J. 2007;154:461-469.

23. Peterson ED, Roe MT, Mulgund J, et al. Association between hospital process performance and outcomes among patients with acute coronary syndromes. JAMA. 2006;295:1912-1920.

24. Lima RS, Watson DD, Goode AR, et al. Incremental value of combined perfusion and function over perfusion alone by gated SPECT myocardial perfusion imaging for detection of severe three-vessel coronary artery disease. J Am Coll Cardiol. 2003;42:64-70.

25. Melikian N, De Bondt P, Tonino P, et al. Fractional flow reserve and myocardial perfusion imaging in patients with angiographic multivessel coronary artery disease. JACC Cardiovasc Interv. 2010;3:307-314.

26. Boden WE, O'Rourke RA, Teo KK, et al. Optimal medical therapy with or without PCI for stable coronary disease. N Engl J Med. 2007;356:1503-1516.

27. Shaw LJ, Berman DS, Maron DJ, et al. Optimal medical therapy with or without percutaneous coronary intervention to reduce ischemic burden: results from the Clinical Outcomes Utilizing Revascularization and Aggressive Drug Evaluation (COURAGE) trial nuclear substudy. Circulation. 2008;117:1283-1291.

28. Qaseem A, Fihn SD, Williams S, et al. Diagnosis of stable ischemic heart disease: summary of a clinical practice guideline from the American College of Physicians/American College of Cardiology Foundation/American Heart Association/American Association for Thoracic Surgery/Preventive Cardiovascular Nurses Association/Society of Thoracic Surgeons. Ann Intern Med. 2012;157:729-734.

29. Hannan EL, Samadashvili Z, Cozzens K, et al. Appropriateness of diagnostic catheterization for suspected coronary artery disease in New York State. Circ Cardiovasc Interv. 2014;7:19-27. 